\title{
Spaces of inclusion and belonging: The learning imaginaries of doctoral students in a multi-campus and distance university
}

\author{
Lucila Carvalho \\ Massey University
}

Cristina Garduño Freeman

University of Melbourne

\author{
Alison Kearney \\ Massey University \\ Mandia Mentis \\ Massey University \\ Roberto Martinez-Maldonado \\ University of Technology Sydney
}

\begin{abstract}
Doctoral studies are often described as solitary and challenging endeavors, dependent on candidates' highly developed skills, self-driven nature, and commitment to engage in years of research activity. A range of university initiatives are specially crafted to support higher research degree students, for example, through digital and physical resources, workshops, group gatherings, and others. Our project examines what constitutes significant places for learning and experiences of inclusion amongst doctoral students, and ways of capturing and sharing these experiences with those learning at distance and on university campuses. Our focus is on connections between social values and the built environment, and on developing ways of expressing these values through students' representations of places for learning. This paper reports on interviews with doctoral students' discussing their connections to oncampus and distance places for learning - within the digital and physical landscapes of a multi-campus university, with provision for both, internal and distance students. Our findings reveal the ways doctoral students navigate the digital and physical realms of university spaces, the places they inhabit and value, their attachments to things, and how these, in turn, influence their feelings of inclusion, belonging, and learning purpose.
\end{abstract}

\section{Introduction}

The completion of a doctoral degree can be described as a challenge, which repeatedly demands candidates' highly developed skills, self-driven nature, and commitment to engage in years of often solitary research activity. The arduous work is evident in the wide range of guides for completing a $\mathrm{PhD}$ (Kearns \& Gardiner, 2006; Mewburn, 2012; Mullins \& Kiley, 2002). Indeed, completing a doctoral degree has been associated with a process of becoming a scholar or a researcher, as $\mathrm{PhD}$ students embody a new identity as experts in a particular field (Barnacle \& Mewburn, 2010). Universities across the globe offer a range of initiatives to support higher research degree students, including for example, digital and physical tools and resources (desk allocation, dedicated spaces for study, computers, access to knowledge databases) and other opportunities, such as workshops, research gatherings, and scholarships. Universities also abound in other less formal opportunities for learning, as students wander through the physical on-campus spaces, finding places for learning in the in-between, leftover, and non-teaching-designed spaces (i.e., cafes, corridors): informal spaces to connect to other students and academics. Similarly, there are also formally designated digital learning environments (e.g., the university’s Learning Management System) which sit alongside online places students create or encounter informally (e.g., Facebook, Instagram, Twitter, Google Hangouts).

This mix of learning opportunities blurs the boundaries between formal and informal, physical and digital. Learning in-between is becoming more noticeable in universities, and this ubiquity of learning has implications to the ways people use and experience the spaces they inhabit (Boys, 2011; Carvalho, Goodyear, \& de Laat, 2017; Gehl, 2011; Massey, 2005). Whilst embracing this more fluid and complex nature of learning, scholars, teachers, supervisors, researchers, and policy makers point out the value in recognising the role of non-formal and informal opportunities in leveraging learning within higher education. Experts believe "that a blending of formal and informal methods of learning can create an 
environment that fosters experimentation, curiosity, and above all, creativity" (Johnson et al., 2016, p. 22). A recent European Commission report presents initiatives and policies to identify ways by which informal learning tasks could be evaluated and incorporated into formal institutions (Johnson et al., 2016). However, as pointed out by Boys (2011), formal, informal, or non-formal learning characterisations are not necessarily useful, as these imply a neat (but artificial) divide between forms of learning, which is often "simplistically translated into spatial/representational design metaphors" (Boys, 2011, p. 3).

Our research involves listening to the ways doctoral students fuse the digital and physical realms. We take a practical orientation to educational design to create knowledge artefacts that embody empirical results and offer students ways to explore and learn from the experiences of others, as well as to share their own. The overarching research aim is to foster informal networked learning practices, community participation and a sense of belonging by encouraging university students to share their learning experiences as members of a community of learners. In this paper, we discuss doctoral students' experiences of on-campus and distance spaces for learning, analysing their connections to the digital and physical landscapes of a multicampus university, which has provision for both internal and distance students. Findings from interviews account for the effects of spaces and places on their perceptions of learning, and will inform the next phase of our research, through the development of a networked learning initiative at the host university.

The next section introduces the notions of community, networks, and place-based spaces for networked learning, in relation to the materiality and spatial configurations of universities, and their significance to inclusive education. We then refer to the spatial and social experiences of doctoral students in particular, before describing our study, participants, and methods. We present three narratives that illustrate the learning imaginaries of on-campus and distance doctoral students and their experiences of places for learning. We conclude the paper with implications for further research.

\section{Framing places and spaces for networked learning}

\section{Networked learning}

Networked learning refers to the use of technology to promote connections and social participation (Goodyear, Banks, Hodgson, \& McConnell, 2004), and people's participation in social communities influences and shapes their identities (Wenger, 2009). Community of practice indicates a social space where members discover and engage in learning partnerships grounded on common interests, while a network does not necessarily evoke an ongoing commitment to a shared interest (Wenger, Trayner, \& de Laat, 2011). Networks are more fluid, and do not require the same explicit collective dimension of communities. The emphasis and value of learning networks are on participants connections to a range of sources, exposure to multiple perspectives, and the opportunities they encounter to help and be helped by others. Community and network are distinct aspects of a social fabric, with community implying more permanent social ties, and network expressing a more transitory character. Each has their own intrinsic values, risks, and challenges, however, a community often involves a network of relationships, and networks are more likely to die if participants' do not share an interest (Wenger et al., 2011).

As students enrol in tertiary studies, they take on a mantle of a new identity and life purpose, which often implies dropping an old one, for example, giving up a job, or relocating to a new town to attend university. They implicitly become a member of a university community of learners, and the values, risks, and challenges associated with this membership unfold through the interplay of structured and emergent interactions. Their learning journey is likely to involve activity that can be both "intentional or incidental ... [where] some learning outcomes are the intended result of participation in a study activity; some are incidental by-products of study activities; some are by-products of activities other than deliberate study" (Goodyear \& Carvalho, 2014, p. 5). The ability to tap into a network of others undergoing similar experiences, may be particularly relevant to doctoral students, helping them overcome isolation (Deem \& Brehony 2000; Meschitti, 2018). Their overall experience is about transformation, including the doctoral task itself, which entails making an original contribution to a body of knowledge. While specialist knowledge is at the basis of doctoral students' identity transformation, other issues associated with effective participation in academic life also shape the emerging scholar. On-campus doctoral students have opportunities to engage in peer learning (Meschitti, 2018) and to generate opportunities for peer learning themselves, as they progress through their candidature. They are immersed in situated learning (Lave \& Wenger, 1991) being exposed to academic practices when sharing office spaces with other students, and 
common areas with academics, when participating in seminars, presentations, and tutorials. Those learning at a distance may rely on technology to gain access to relevant networks.

\section{University as a city: Places, spaces, and inclusion}

Universities and other tertiary institutions were never designed for everyone. They were originally intended for a small elite minority of citizens (usually male, white, and of economic means) and because of this, the structures, values, practices, and physical spaces of these institutions are often set up to support and enable this group of students, while excluding and marginalising others. Over the last 50 years, calls have been made for more equitable forms of education and in particular, the notion of inclusive education has dominated this discussion. Inclusive education focuses on recognising and dismantling educational exclusion (Slee, 2011), and ensuring that personal and social circumstances, such as disability, ethnicity, religion, gender, and poverty, do not act as barriers to students achieving their educational potential. Inclusive education is not focused on changing or remediating learners to ensure that they fit into an educational environment. Rather the emphasis is on creating education environments where all students can meaningfully participate, contribute, and learn. It is about transforming and creating environments that are better able to meet the needs of more diverse student populations. Identifying those barriers that act to exclude and marginalise some students from and within universities and other tertiary institutions is critical for the development of inclusive education systems and of more inclusive and equitable societies (United Nations Educational, Scientific and Cultural Organization, 2017). Access to education, including higher education, brings considerable advantages to both individuals and societies. When compared to those who do not have access to quality education, well-educated people have higher incomes and better health, and report higher levels of well-being and happiness (Organisation for Economic Co-operation and Development, 2007).

Universities are also particular kinds of entities, with a specific spatial (physical) configuration (the campus) and a social configuration, and with many distinct hierarchies. They hold substantial identity as places of transformation. This is pertinent to the way students experience the university as an institution. We argue this is felt most acutely by doctoral students, who are not only at a university as students, but many aspire to become members of the academic staff. As an entity, the university could be considered as a neighborhood, a town or even a city, especially when it has multiple campuses and operates at a distance mode, and yet, needs to be seen as a singular coherent institution. The efforts and spending on university branding, their corporatisation across the globe, are evidence of the importance placed on this notion of identity.

In examining students' experiences of the spatial and social university structures, it is important to distinguish between place and space. Whilst place relates to something concrete, realised, and experienced, space usually evokes a more abstract, generalised, and conceptual meaning (Carvalho et al., 2017). Place implies a relationship between a human and a spatial configuration, in contrast to space as a more figurative notion (Cresswell, 2005). A sense of intimacy and identity is connected to place, and this social/spatial blurring is essential, offering a certain slipperiness to the notion of place, which allows us to carry its use over also to non-physical spaces, such as online. Importantly, spaces and places can no longer be seen as disconnected to what students do, they cannot be left as the mere backdrop to the real action. Understanding the role of materials in learning is crucial: how objects and artefacts transform and modify people's learning trajectories, as highlighted by the socio-material and spatial turns in educational research (Fenwick, Edwards, \& Sawchuk, 2011; Sørensen, 2009).

Traditional understandings of how and where learning takes place in higher education are being challenged and reconceptualised. Bayne, Gallagher, and Lamb's (2014) research explores the ways distance students interpret the space of the University of Edinburgh: a traditionally based on-campus institution. They argue that the physical campus has both symbolic and material relevance for those at distance, including students who may have never physically attended the campus. Students create their own versions of the "spatial certainties of bounded, campus space" (Bayne et al., 2014, p. 569), and yet alongside these "new proximities" enabled by online distance education, there are also other topologies, which are part of distance students' stories about what it means for them to be at university. Entanglement emerges as distance students' symbolic constructions of a physical campus are likely to be mediated through formal and informal online representations, some of which may be grounded in formal one-way mode of 
communication (e.g., university's website); formal two-way mode (e.g., learning management system), and informal two-way mode (e.g., Facebook pages, listservs, Twitter).

In examining place-based spaces for networked learning, we acknowledge that people's experiences of spaces are often extended by networked technologies, and our interest lies on the ways doctoral students personalise and make these spaces their own, as a space becomes their place for learning. These connections between bodies, minds, and technologies have been theorised by scholars in embodied cognition (Clark, 2008; Kirsh, 2013), where people's concepts and beliefs, their ideas and understandings about the world they inhabit, are seen as connected to their perceptual-action experiences with things. In other words, their understandings of the world are essentially situated through tool-mediated interactions (Kirsh, 2013). As such, what one does is often grounded in cognitive processes that rely on people's perceptual system, influencing the ways people's actions align with predictions made about the surroundings (Markauskaite \& Goodyear, 2017). A question then remains as to how the on-campus materiality reflects and affects the experience of both, on-campus students and those remotely located.

\section{The spatial and social fabric of doctoral students}

Doctoral students are bounded to distinctive social norms, characterised by specific privileges and restrictions, which often do not apply to other postgraduates and undergraduates. Spatially, they are usually the only students with assigned workspaces and who are able to access staff resources such as printers, stationary, and the staff room. At the same time, they are kept at a distance and not always recognised as true academics, which perhaps makes these students vulnerable to isolation and exclusion. Indeed, for doctoral students, issues of inclusion are prevalent across the world, with studies highlighting the significant challenges faced by women and minority postgraduate students in the United States and Europe (Danowitz \& Tuitt, 2010; Elg \& Jonnegard, 2003). Doctoral students in the United Kingdom face tensions, such as financial pressures, isolation, institutional support, and perceptions of disadvantage, which are much more pronounced among minority groups (Mattocks \& Briscoe-Palmer, 2016). International doctoral students in Canada report an ambiguous sense of self, belonging, and educational purpose when participating in transnational academic and social spaces of the university (Phelps, 2016). In New Zealand, challenges to inclusion are particularly evident for Māori and Pacific (indigenous) doctoral students as evident in the comparatively low participation and completion rates (Theodore et al., 2018). For Māori students, in particular, issues can be framed in spatial terms, and requires an understanding of the multiple spaces in which Māori doctoral students' research and supervision take place (Middleton \& McKinley, 2010). Success for Māori doctoral students requires culturally appropriate approaches to supervision, and the creation of environments that support students to work "at the interface of academic and traditional knowledges" (McKinley, Grant, Middleton, Irwin, \& Williams, 2011, p. 128).

Such experiences in doctoral candidatures seem to reinforce why peer learning and support is also so valuable for this cohort. Importantly, the advice from more advanced students to those at early stages can be critical, and the physical space has a role in facilitating these conversations. As pointed out by Barnacle and Mewburn (2010):

[T] he spatial arrangements of built environments will contribute to knowledge translation and identity formation differently, depending, for example, on the extent of co-location between doctoral candidates and their proximity to academics and technical staff or, alternatively, whether particular hierarchies are challenged or undermined by whether doctoral candidates have access to the staff tea room. While there is broad recognition that factors associated with the research environment, for example, impact on research candidate learning, the actual significance of such factors is not always well understood. (p. 443)

Social, cultural, institutional and personal factors can all play a role in doctoral students' sense of isolation or belonging. Understanding the doctoral students' unique experiences will help to design a more inclusive doctoral environment. Listening to the voice of students is an important aspect of this research.

\section{Project description}

Our project examines what constitutes significant places for learning' amongst doctoral students, their experiences of inclusion and belonging, and ways of capturing and sharing these experiences of both 
distance and on-campus students. We are interested in connections between social values, community values, and the built environment (Carvalho \& Garduño Freeman, 2018), and ways of expressing these values through students' digitally curated representations of places for learning. In reframing social values as a dynamic activity and located within the university community, we are interested in capturing students' voice and finding ways of designing for informal networked learning. The overarching study poses the following research question:

How can we encourage informal networked learning practices, and promote and assess social value within a university environment?

We further pose the following associated sub-questions:

a. How do distance and on-campus students experience 'places for learning' at the university?

b. How do distance and on-campus students experience 'places of inclusion' at the university?

c. How can technology support students in sharing their experiences of 'places for learning and inclusion'?

This paper addresses findings associated with questions (a) and (b) above. Question (c) is addressed in our most recent work, where we are analysing students' use of an app called CmyView (Carvalho \& Garduño Freeman, 2018) to share their places for learning and inclusion with others.

\section{Study design, participants. and data collection}

The study involved eight in-depth semi-structured interviews with doctoral students distributed across campus $1(N=3)$, campus $2(N=2)$, and distance $(N=3)$, from different disciplinary areas of research in humanities and social sciences. Doctoral students were contacted and invited to participate in the project via the university mailing system and face-to-face requests. Individual interviews lasted between 30 minutes and 1 hour. All interviews were audio-recorded and transcribed for analysis.

Narrative inquiry supported data analysis and interpretation, with participants' voices being drawn from the data and intentionally woven into three learning narratives (Clandinin, 2013). Taylor's (2007) notion of social imaginary helped develop these narratives, which are grounded in the experiences reported in three interviews. Social imaginary focuses on "presumptions that people have about their collective social life" (Vertotec, 2012, p. 305). It is about:

[T] he ways that people imagine their social existence, how they fit together with others, how things go on between them and their fellows, the expectations that are normally met, and the deeper normative notions and images that underlie these expectations. (Taylor, 2007, p. 23).

Analysis explored emerging themes related to what it means to learn at this university, the nature of students' connections to the institution (as a place and as a community), the significance of places for learning and experiences of inclusion for distance and on-campus learners.

Three interviews are reported. Two participants were on-campus students (Student 1 and Student 2) and a third one was remotely located (Student 3). All students were over the age of 30 and both genders were represented. Two participants were studying part-time and one was a full-time student. All have been at the university for at least 5 years. The Human Research Ethics Committee of the host university granted approval for the conduct of this research.

\section{Analysis and discussion}

\section{Narrative 1: A learning imaginary where synergies flourish in shared spaces}

Student 1 identified the $\mathrm{PhD}$ room as the primary/preferred space for learning. Student 1 reflected on having a dedicated space, associating it to a professional outlook - a place where doctoral students activity is seen as a job:

I don't work well at home unless I am really forced to. It is too comfortable at home, and there is too much stuff to do, I mean, too much distraction, socially. But I prefer the 
professional environment here where you just come in and carry on. Well, we treat our studies as our jobs, very professionally. There are certain times we come and certain times we have a break.

Student 1 also welcomed this as a shared space, recognising the opportunities it creates in establishing and strengthening formal and informal connections with peers. This participant alluded to the intimacy of informal exchanges, which intensify students' togetherness and sense of community, where the space is valuable for support, sharing experiences and peer learning:

The synergy that the group provides, it is support, it is a mentor support at times. Now and then we just discuss politics and everybody chips in, everybody sort of drops from their computers and turns around and have a discussion which is quite healthy. And then we learn from what other people are, what their social orientations are, what their educations are, not so much privacy but about what their opinions are on issues and that's all part of learning. It is motivational and synergetic.

Feelings of isolation were reported by Student 1, through issues associated with a lack of cultural support, in comparison to previous experiences at another university. This participant reflected on taking initiatives to try to fulfil this gap personally, and for other academics/students to have a cultural support group:

I liaise with other lecturers [from my cultural group] here on-campus ... sometimes we meet and we provide that support, you know, that cultural support, which is something that is all lacking here. So I had to go and suggest to the ... lecturers here, to set up a cultural group to bring your ... students, because the community [from my cultural group] is departing from this university big time. And it is really good for me, as an educator [from my cultural group], to see that some of that community is following us in learning from here. So I liaise with those guys here from different schools, Psychology ... I did all my degrees at [another university]. I didn't mean to come here, I only came to [this university] because of the professor who was prominent in my field. I started my $\mathrm{PhD}$ there at [the other university], because the support system is there, the community is there, and that university is very prominent in providing that support, outside academia. ... So I had to go and talk to the lecturers here, and I asked the question - what are our numbers like here? What are the numbers of students [from my cultural group] here? And why are there not more here? ... I believe [this university] could offer something in that too.

A need for quietness is also identified. Student 1 recognises and welcomes the proximity to like-minded others and a synergy that comes with sharing a physical area, at the same time that there is value in the silence, at some moments:

Well, we don't really complain much, you know, so long as there is a good space, you know, where there is peace and quiet, we will do our own learning. So on that room [the PhD room] it is quite a very good room for us. But I suppose it depends on the stage of your studies also. You know, for me at this level, at this stage of my work, I just know where the space is, I know what the energy is and all the people around. I just come in and sit, and just carry on with the work. Because we know the area, we know the space.

We have a $\mathrm{PhD}$ room here, you know, which is quite a good space for us. ... all the $\mathrm{PhD}$ students are there, also, so we are pushing each other, you know, it is quite a good space. [It is valuable for] effective writing and also we are with other students - it is just the synergy that we provide, that other students provide. Apart from that, you are in your own space, and you can develop quite a lot and achieve quite a lot within that space. ... At a $\mathrm{PhD}$ level you know is all about thinking, and abstract thinking, you know, so there will be a lot of distractions. I usually use the library sometimes, but it is very distracting.

Hanging out on-campus allows students to (informally) connect to academics, supervisors, and other researchers. The staff common room was identified as a space to connect and network with others. Student 1 also highlights the importance of other on-campus spaces: 
For me being on-campus allows me to have access to supervisors and help.... We connect here [staff room] with academics, they have seminars, which is good. ... It is very important ... because networking is part of your learning, you've got to do that, especially in academia, because they are all in different functional departments, different intelligences, you've got to share those ideas, and you learn from others too.

At the cafeteria we hang out with friends, [at] the [on campus] Café. ... There is where we all hang out with like-minded students and other students. There is a mix of outsiders, community, corporates, and students there, it is quite nice. It is just the communication and energy that other people bring. You know, I don't go to 'students only' things. It is different. Different energy. You do a lot of communication with outsiders also in that place. There is a different, level of people.

\section{Narrative 2: A learning imaginary where materiality shapes identity and guides purpose}

Similarly, Student 2 also highlights experiences of studying in a dedicated space, comparing it with working from home. This participant values the sense of choice and purpose that the university spaces offer. Student 2 reflects on places where one can focus, and yet have enough autonomy and flexibility to decide when/how their workflow activities unfold:

Because here it is like this, I come in the morning and I go at night - I can choose what time I want to really study, or what time I want to less study, what time I want to just have my lunch. I have more amount of time and I have more control over my time. But when I was at home I know that for example, if my partner or if my flatmates arrived at 6 o'clock, it wouldn't be any more time really for working, because they would distract me.

Space is also valued through strong ties to materials. Having "my things" is important and a dedicated space influences this student's feelings of a sense of belonging - this is "my space". In addition, an orderly character is associated with a strong sense that materials support learning:

My favourite space is the $\mathrm{PhD}$ room, because I have my computer over there and I have my desk of course, and you know because is my thing I feel some sort of, a sense of also belonging to that space, which is mine.

Student 2 sees the function of the $\mathrm{PhD}$ room as different from other university spaces. Two spaces $(\mathrm{PhD}$ and staff rooms) seem to fulfil different needs, for example offering a welcome change, an opportunity to feel better, after hours concentrating on work - suggesting a mindset that is linked to the surrounding materials and built environment:

[S]ometimes when I feel so tired from that space, because I'm spending long hours over there ... I like to try this common room, if it is quiet and no one else is here. But because, I mean, my computer is there and most things happen in the computer ... I use a desktop but I've also a laptop but I always use my desktop. Sometimes if I want to do something which isn't related to my own $\mathrm{PhD}$ then I use my laptop and seat here, because that is a nice change of space. ... That place $[\mathrm{PhD}$ room] is a more practical sort of space for me, because ... I have my desk, I can put my prints, my books and everything close to myself and I have my own computer. In terms of practicality that space is the best one, but I like this space [staff room] better because maybe is something new for me, because is not a place that I use every day. It brings diversity to me when I work here it feels better, but maybe that space is more practical because I have everything around me.

A feeling of being over powered by the materials and space, particularly after repeated hours of work, also requires a change of environment:

Sometimes there were occasions I really didn't like to go to that $[\mathrm{PhD}]$ room really, because I feel so exposed, you know, to the whole space. And I feel I don't want to see that space, because here [staff room] is a bigger space and a nicer view, because we don't have that much of a view over there. ... The window overlooks the library and my desk is like this, in 
front of the wall, and I don't have a nice view really. Sometimes I feel I don't want to be there anymore because I spend long hours there so here is very nice, whenever I have something to read which is not in the screen, I jump in here if it is free.

Overall, Student 2 shows strong ties with the physicality of the spaces, which are evident through statements such as "being at the university physically" connected to "being a student":

I've never thought about any other source of being a student. In my mind being a student is defined by being here physically ... I don't know why, but I never think about any other way of studying rather than doing it physically, maybe because I have enough time to come and attend to the space.

Feelings of isolation are expressed by Student 2 in relation to working from home for longer periods. The physical campus is linked to interpersonal relationships, to opportunities to encounter others:

There was a period, actually, of maybe about 6 months, something like this, that I came less often here. And I worked one day from home and one day from here, because I was living far from the campus. But for me over the time that I was working from home, I felt a bit isolated, I felt I was by my own, I had no social life, because I was mostly at home not seeing anyone.

Similar to Student 1, Student 2 also mentioned the importance of quietness and enjoying the shared space the most, when alone:

That is a shared space, there are also other people over there, [but] I enjoy the most when no one is there, which is in some occasions over the weekends or later at nights. I enjoy it better when I am alone.

The staff common room is Student 2 preferred space for casual encounters with academics, supervisors and other researchers. Such unintentional social endeavours are highly valuable, and seen as opportunities to connect to others and share experiences:

This common room, I think again, is the place where I communicate the most with other people, because people are coming and going ... and sometimes you see people and start to talk specifically, I mean, when you are doing your lunch or making a tea, and there is staff ... there is a chance to pop to different people. I have found lots of friends here really in this common room. Sometimes I've found my supervisor here which was a good thing because I also could talk to him about my own work, and sometimes not just about my own work, but about other things happening, around politics and other sorts of things. My main place for socialising is here, but I don't come here basically to socialise, I come to do something else and then ends up socialising, [but] it wasn't like by intention. ... It is a type of socialising and seeing people, at the same time it is somehow related to my own work, because sometimes I discuss my own work with them. Sometimes, they are discussing their work but [it] makes a sort of contribution to my work and you know because you are talking to people about different things and sometimes over these conversations some things come to your mind. It is not intentionally, it is not the purpose of affecting my learning process or my research work, but sometimes they connect.

\section{Narrative 3: A learning imaginary that trespasses physical-digital boundaries - a doctoral at a distance}

In despite of being a distance student, Student 3's narrative has many similarities to the previous two, particularly in relation to the physicality of materials around this participant. Student 3 values a dedicated place for learning at home, even if her current arrangements are not ideal:

We've had a couple of issues since we moved here, so we are in this tiny little granny flat, with borrowed furniture, trying to build our house, and through a variety of circumstances that's been held up. ... I am just looking across to where I work which is basically a whole 
table with my laptop on it, and a tiny little bookcase, and boxes and books everywhere and papers on the floor. I wouldn't call that my favourite [laughs]. It is actually meant to be our dining room, but it is where I work ... it's got everything there, my laptop is open. It's set up how I like it. I've raised a little bit, [so] it's more convenient to work at. I've positioned things to hand, quite close, being on the floor or whatever, I know that when I sit down there I work, most of the time. ... In front of me, I've got my research questions - sticky notes, and then to my right hand side I've got a little noticeboard with a lot of words and links.

While at the moment "there are no set places where things belong and they just have to be in a box somewhere", Student 3's narrative highlights the need to have materials at hand, in the surrounding areas: "I try to position piles and things so I can grab them". This student longs for the time when there was a different situation, and also hints an organisational character associated with the materials:

[Elsewhere] I had a set space, and I had all my things, and I knew where everything was. Papers and books didn't have to be stored away into boxes in the bedroom because they were out in shelves, so it hasn't been that easy studying over here at a distance, because of our personal circumstances ... but on the other hand, despite all the stresses involved in trying to build a house, it has been a retreat, I can take myself away into my books and studying ... I've looked beyond the mess now.

Student 3 has restricted contact with academic staff, with most supervisory meetings being held online. Nevertheless, Student 3 managed to establish a good network of supporters, which includes face-to-face and online groups. This participant attends monthly meetings at a local café, with doctoral students from a range of universities, and also other physically-based opportunities organised via the university:

It's just a serendipitous occasion that we went to a conference, so we were seating around having breakfast and turned out that most of us at a table were from [the same city] which is very unusual. So we set up this group and we've met once a month. And in fact we met yesterday and we just have a coffee in a café ... and some of the members go in early and write and we have our meeting. It is always a set time for an hour, because otherwise just drags on ... and we always leave the meeting with sort of aims that we'd like to achieve for the next meeting. And as I say, some people stay on again and write in that environment, I am yet to do that. But I really enjoy that face-to-face time, it is a lot easier to chat. We always talk about doctoral issues, or in and around doctoral issues. It could be anything from methodology to bedtime routines, I mean there is all sorts of issues, but it is always about doctoral studies... there is probably a group of about 8 , I suppose and I really enjoy that ... plus it means I get to meet local people.

I have just been recently to [the university campus] actually, to a doctoral event, that the (department) runs, that's is an annual event. ... I probably count - in a 12 month period - I probably go there at least maybe once or twice, which isn't a lot, because my supervisory meetings I do via Skype.

Student 3 also mentions the value of an online group, recently organised by the Graduate Research Services, but stresses that there is an easier flow to face-to-face interactions:

The other group I meet with, online, every two weeks, is this initiative ... it's got up to 7 now, which I think is the maximum online, and we tune-in through Zoom, again for an hour, on a Tuesday morning, and again we talk about doctoral issues. But somebody has to facilitate all the time, and I decided that I didn't want to have that responsibility each time. So we spread it around, we each take a turn to facilitate... and when I say facilitate is really just might be a couple of questions ... let's say methodology, I remember we did that once what sort of methodology are we all using? ... And that usually leads to a discussion everybody in our group talks, which is great. Having said that, I haven't been able to go to the last three meetings, but I know that the group is meeting. ... What I've noticed is, when you meet online, it doesn't flow as easily as if you meet people face-to-face, it is just the nature of what it is, but is better than nothing ... one of them is in [city 1] other in [city 2] 
and other in [city 3], you name it, they are everywhere. And we just tune-in and what we have in common is the fact the we are doing doctoral studies.

\section{Bringing the narratives together}

The narratives of on-campus and distance students describe their attachments to the university's physical and online spaces. While these students value the material and digital elements, their experiences also stress the importance of the social through a sense of community, and the functional character associated with the emergent activity in various spaces. In other words, these students allude to places for learning in relation to socially, epistemically, and physically situated experiences. Their active participation in the practices of the university community shapes their identities as students and as emerging scholars (Wenger et al., 2011). The distance student referred to physical locations (e.g., the local café and the on-campus workshops for doctoral students), and an online university space for fortnightly meetings with other doctoral students from the host university. For the on-campus students, identity seems strongly bounded to the allocated $\mathrm{PhD}$ space, reassuring them of both a definite location and role, which positions them alongside like-minded others. Edwards and Usher (2008) remind us of connections between location, role and identity:

If we are a student, we are part of something, we belong within an institution. That sense of belonging is important in establishing both a boundary and a sense of identity. Belonging provides a certain status that is important to ourselves and for negotiating boundaries with others. (pp.142-143)

This sense of identity is reflected through the mix of social, epistemic and physical elements in the students' learning networks (Goodyear \& Carvalho, 2014). Student 1 speaks of the value of being on-campus through a narrative that draws a parallel of the doctoral experience to a job-like endeavour (social). This participant's motivation for choosing this university is associated with the presence of a distinguished professor, whose knowledge is highly valued (social and epistemic). Student 2 mentions strong connections to "my things", "my space" (physical), and how these in turn, support a sense of belonging (social). This sense of place is echoed by Student 3 in reference to the participant's home space. Their individual experiences highlight how the physical spaces and the material elements contribute to their learning in subtle ways, through the positioning, allocation, sharing, and opportunities afforded by the serendipity of encounters with others. All students refer to a complex network of elements that influence their emergent learning experiences, but the spatial arrangements of the built environment contribute to their knowledge construction and identity formation differently (Barnacle \& Mewburn, 2010). All of them experience proximity to other doctoral candidates and have opportunities to interact with academics, either on a daily basis or at pre-arranged annual/monthly/fortnightly events. The value of these encounters is noticed when on-campus students refer to learning in-between (Boys, 2011; Gehl, 2011), and the ways they use and experience university spaces. The fluidity of on-campus spaces is also connected to mobile technology. Having a laptop allows students to travel around, make choices and assign different learning purposes to different spaces, when students feel the need for a change in their routines. But it is also in the non-formal moments, while preparing lunch or tea, that incidental learning emerges, forging new connections, bringing new insights, strengthening their sense of belonging to this community. This appears less so in the narrative of the distance student, where going to a café to meet others or attending the annual workshops for doctoral candidates are not casual encounters, but (semi) formalised ones.

The two on-campus students expressed feelings of isolation when located outside campus, or when working from home. The distance student also refers to solitary moments, but importantly, reports having built a network of connections around. The theme of isolation also emerged through the perceived lack of cultural support at the host university, where issues of inclusive education are raised. While being on-campus affords perhaps better opportunities for networking with like-minded others, some of these connections are not effortlessly forged, requiring active participation to locate and bond to a community of significant others - as the cultural support group mentioned by Student 1. Finding ways of supporting these communities, both online and within the physical spaces, or making them more visible, may help strengthen doctoral students' sense of belonging to the university community. The role of community, or a network, in supporting these students should not be undermined (Goodyear et al., 2004; Wenger, 2009; Wenger et al., 2011). 


\section{Final remarks and implications for further research}

In becoming a scholar or a researcher, doctoral students go through transformations, taking on a new identity linked to their particular area of expertise. While the research literature recognises the influence of the physical environment on a candidate's learning, such impact is not yet well understood (Barnacle \& Mewburn, 2010). Nevertheless, people are more likely to thrive when they feel connected, when they feel they belong, and as they are able to share learning experiences with physically co-located or remote others (through online interactions). It is therefore crucial that we find ways of encouraging students to explore, connect and learn from the experiences of others, and to share their own stories. The learning narratives reported in this article, are informing our thinking about ways of encouraging informal networked learning practices within the host university. The next phase of this research extends and complements the work reported here through working with these participants and others, to produce a second iteration of their learning narratives. This involves doctoral students composing digital artefacts about their experiences of significant places for learning and experiences of inclusion, to be shared via the CmyView app (Carvalho \& Garduño Freeman, 2018) amongst a community of learners.

\section{References}

Barnacle, R., \& Mewburn, I. (2010). Learning networks and the journey of 'becoming doctor', Studies in Higher Education, 35(4), 433-444. https://doi.org/10.1080/03075070903131214

Bayne, S., Gallagher, M., \& Lamb, J. (2014). Being “at” university: The social topologies of distance students. Higher Education, 67(5), 569-583. https://doi.org/10.1007/s10734-013-9662-4

Boys, J. (2011). Towards creative learning spaces: Re-thinking the architecture of post-compulsory education. Abingdon: Routledge.

Carvalho, L., \& Garduño Freeman, C. (2018). CmyView: Learrning by walking and sharing social values. In N. Bonderup Dohn, S. Cranmer, J. Sime, M. de Laat, \& T. Ryberg (Eds) Networked learning: Reflections and challenges (pp. 167-186). Cham: Springer. https://doi.org/10.1007/978-3-319-74857$3 \_10$

Carvalho, L., Goodyear, P., \& de Laat, M. (Eds) (2017). Place-based spaces for networked learning. New York, NY: Routledge.

Clandinin, J. (2013). Engaging in narrative enquiry. Walnut Creek, CA: Left Coast Press.

Clark, A. (2008). Supersizing the mind: Embodiment, action, and cognitive extension. Oxford: Oxford University Press.

Cresswell, T. (2005). Place: A short introduction. Malden, MA: Blackwell.

Danowitz, M. A., \& Tuitt, F. A. (2010). Moving towards inclusive excellence in doctoral studies. In S. Katila, S. Meriläinen, \& J. Tienari, Making Inclusion Work. Cheltenham: Edward Elgar Publishing. https://doi.org/10.4337/9781849806862.00009

Deem, R., \& Brehony, K. (2000). Doctoral students' access to research cultures - Are some more unequal than others? Studies in Higher Education, 25(2), 149-165. https://doi.org/10.1080/713696138

Edwards, R., \& Usher, R. (2008). Globalisation \& pedagogy. Space, place and identity. London: Routledge.

Elg, U., \& Jonnergard, K. (2003). The inclusion of female PhD students in academia: A case study of a Swedish university department. Gender, Work and Organization, 10(2), 154-174. https://doi.org/10.1111/1468-0432.00009

Fenwick, T., Edwards, R., \& Sawchuk, P. (2011). Emerging approaches to educational research: Tracing the sociomaterial. Abingdon: Routledge.

Gehl, J. (2011). Life Between buildings: Using public space. Washington, MA: Island Press.

Goodyear, P., Banks, S., Hodgson, V., \& McConnell, D. (Eds.) (2004). Advances in research in networked learning. Dordrecht: Kluwer Academic Publishers.

Goodyear, P., \& Carvalho, L. (2014). Framing the analysis of learning network architectures. In L. Carvalho, \& P. Goodyear (Eds.) The architecture of productive learning networks (pp. 48-70). New York, NY: Routledge.

Johnson, L., Adams Becker, S., Cummins, M., Estrada, V., Freeman, A., \& Hall, C. (2016). NMC Horizon Report: 2016 Higher Education Edition. Austin, TX: The New Media Consortium.

Kearns, H., \& Gardiner, M. (2006). The 7 secrets of highly successful research students. Adelaide: Staff Development and Training Unit, Flinders University.

Kirsh, D. (2013). Embodied cognition and the magical future of interaction design. ACM Transactions on Computer-Human Interaction, 20(1), 3:1-3:20. https://doi.org/10.1145/2442106.2442109 
Lave, J., \& Wenger, E. (1991). Situated learning: Legitimate peripheral participation. Cambridge: Cambridge University Press.

Markauskaite, L., \& Goodyear, P. (2017). Epistemic fluency and professional education: Innovation, knowledgeable action and actionable knowledge. Netherlands: Springer.

Massey, D. (2005). For space. London: Sage Publications

Mattocks, K., \& Briscoe-Palmer, S. (2016). Diversity, inclusion, and doctoral study: Challenges facing minority PhD students in the United Kingdom. European Political Science, 15(4), 476-492. https://doi.org/10.1057/s41304-016-0071-x

McKinley, E., Grant, B., Middleton, S., Irwin, K., \& Williams, L. (2011). Working at the interface: Indigenous students' experience of undertaking doctoral studies in Aotearoa New Zealand. Equity \& Excellence in Education, 44(1), 115-132. https://doi.org/10.1080/10665684.2010.540972

Meschitti, V. (2018). Can peer learning support doctoral education? Evidence from an ethnography of a research team, Studies in Higher Education, 1-17. Retrieved from http://www.tandfonline.com/10.1080/03075079.2018.1427711

Mewburn, I. (2012). How to tame your PhD. London: Akimbo Productions.

Middleton, S., \& McKinley, E. (2010). The gown and the korowai: Māori doctoral students and the spatial organisation of academic knowledge. Higher Education Research \& Development, 29(3), 229243. https://doi.org/10.1080/07294360903510590

Mullins, G., \& Kiley, M. (2002). It's a PhD, not a Nobel Prize: How experienced examiners assess research theses. Studies in Higher Education, 27(4), 369-386. https://doi.org/10.1080/0307507022000011507

Organisation for Economic Co-operation and Development (2007). No more failures. Ten steps to equity in education. Retrieved from http://www.oecd.org/education/school/nomorefailurestenstepstoequityineducation.htm

Phelps, J. (2016) International doctoral students' navigations of identity and belonging in a globalizing university. International Journal of Doctoral Studies, 11, 111-14. https://doi.org/10.28945/3397

Slee, R. (2011). The irregular school. Exclusion, schooling and inclusive education. London: Routledge.

Sørensen, E. (2009). The materiality of learning: Technology and knowledge in educational practice. Cambridge: Cambridge University Press.

Taylor, C. (2007). Modern social imaginaries. Durham: Duke University Press.

Theodore, R., Taumoepeau, M., Kokaua, J., Tustin, K., Gollop, M., Taylor, N. ... Poulton, R. (2018). Equity in New Zealand university graduate outcomes: Māori and Pacific graduates. Higher Education Research \& Development, 37(1), 206-221. https://doi.org/10.1080/07294360.2017.1344198

United Nations Educational, Scientific and Cultural Organization (2017). A guide for ensuring inclusion and equity in education. Paris: UNESCO. Retrieved from https://unesdoc.unesco.org/ark:/48223/pf0000248254

Vertotec, S. (2012). 'Diversity' and the social imaginary. European Journal of Sociology, 53(3), 287-312. https://doi.org/10.1017/S000397561200015X

Wenger. E. (2009). A social theory of learning. In K. Illeris (Ed.) Contemporary theories of learning: Learning theorists - in their own words. (pp. 209-217). New York, NY: Routledge.

Wenger, E., Trayner, B., \& de Laat, M. (2011). Promoting and assessing value creation in communities and networks: a conceptual framework (Vol. 18). Heerlen: Open Universiteit.

Corresponding author: Lucila Carvalho, 1.carvalho@massey.ac.nz

Australasian Journal of Educational Technology (C) 2018.

Please cite as: Carvalho, L., Garduño Freeman, C., Kearney, A., Mentis, M., \& Martinez-Maldonado, R. (2018). Spaces of inclusion and belonging: The learning imaginaries of doctoral students in a multicampus and distance university. Australasian Journal of Educational Technology, 34(6), 41-52. https://doi.org/10.14742/ajet.4483 